\title{
A simple method for fabricating custom sectional impression trays for making definitive impressions in patients with microstomia
}

Vinay Chila Bachhav ${ }^{1}$

Meena Ajay Aras ${ }^{2}$

\section{ABSTRACT}

Objective: A maximum mouth opening that is smaller than the size of a complete denture can make prosthetic treatment challenging. This article describes a simple technique used to fabricate maxillary and mandibular custom sectional impression trays for making definitive impressions in patients with microstomia. (Eur J Dent 2012;6:244-247)

Key words: Dental impression technique; microstomia; definitive impression; sectional impression trays.

\section{INTRODUCTION}

Microstomia is defined as an abnormally small oral orifice. ${ }^{1}$ This disorder is described as a reduction in the oral aperture size associated with facial burns, diffuse scleroderma, traumatic injuries, and surgical reconstruction involving the orbicularis oris muscle. Microstomia can result in multiple debilitating sequelae such as inability to masticate, drooling, speech problems due to poor articulation, impaired delivery of oral hygiene and dental care, and psychological problems secondary to facial disfigurement. ${ }^{2-8}$

Several methods of prosthodontic treatment for microstomia patients have been presented, and numerous devices to expand the oral commissure

1 Department of Prosthodontics, Guru Gobind Singh College of Dental Science and Research Center, Burhanpur, Madhya Pradesh, INDIA

2 Department of Prosthodontics, Goa Dental College and Hospital, Bambolim, Goa, INDIA

- Corresponding author: Dr. Vinay Chila Bachhav Department of Prosthodontics, Guru Gobind Singh College of Dental Science and Research Center, Burhanpur-450331 (M.P.) INDIA

Tel: +91942 2783856

Email: vinaybachhavagmail.com have been described. 3,9-12 The prosthetic rehabilitation of microstomia patients presents difficulties at all stages, from preliminary impressions to prosthesis fabrication. ${ }^{13}$ Because such patients have small oral openings, using conventional methods for making definitive dental impressions and fabricating dentures may be extremely difficult. Making the accurate impressions represents the initial difficulty in the prosthetic rehabilitation of such patients.

The recommended techniques for obtaining preliminary impressions for microstomia patients include the use of modeling plastic impression compound, the use of stock impression trays with heavy and light body silicone impression materials, and flexible impression trays with silicone putty.

The casts obtained from these preliminary impressions are then used for making custom sectional impression trays. These trays typically consist of 2 locking devices or assemblies, 1 situated anteriorly and the other posteriorly, which join and provide stability to both the sections of the trays. These 2 sections of the trays are assembled and disassembled intraorally. After the definitive im- 
pressions are made, these trays are reassembled extraorally and are poured in dental stone to obtain definitive, working casts.

Several studies have described various techniques that are used for making custom sectional impression trays. ${ }^{14-18}$ Different devices used for connecting the custom sectional trays include hinges, ${ }^{14}$ plastic building blocks (Lego; Lego Systems Inc, Enfield, Conn., USA), ${ }^{15,16}$ orthodontic expansion screws, ${ }^{17}$ or locking levers. ${ }^{18}$

This article describes a simple, cost-effective, and time-saving method for fabricating custom sectional impression trays using easily available dual die-pins and sleeves as potential devices for interlocking the sectional trays. The locking mechanism design includes an anterior locking assembly for the maxillary and mandibular custom trays and a posterior locking assembly for only the maxillary custom tray.

\section{TECHNIQUE}

1) By using the conventional method, fabricate the maxillary and mandibular custom sectional impression trays by using autopolymerizing acrylic resin (DPI-RR, Dental Products of India, Mumbai, Indial on the preliminary casts.

2) Make the handles of the trays Iminimum dimensions with $13 \mathrm{~mm}$ height, $10 \mathrm{~mm}$ length, and $10 \mathrm{~mm}$ width) such that they incorporate the metal sleeves of the dual die-pins (M.R. ${ }^{\mathrm{TM}}$ Dual Pin and sleeves, Select Dental).

3) Section both the custom impression trays at the midline by using a diamond disk (DFS, Germany).

4) Steps in the fabrication of the anterior lock assembly in the maxillary and mandibular custom sectional impression trays:
- The assembly basically consists of 2 dual diepins and 2 sleeves. Closely juxtapose the 2 sleeves such that the smaller keyway of 1 sleeve faces the larger keyway of the other sleeve. Join these sleeves by inserting the 2 dual die-pins and making the assembly a rigid joint (Figure 1a-d).

- Make a slot on the inside portion of the handles on each half of the sectioned custom trays to incorporate the sleeve (Figure 2a \& b).

- Attach the sleeves in the slots by using the autopolymerizing acrylic resin as mentioned previously (Figure 3).

- Verify the position of the attached sleeves by inserting die-pins such that the halves juxtapose precisely in both the sectioned trays.

- Fabricate an anterior assembly for the mandibular sectional tray in a similar manner (Figure 7).

5) Steps in the fabrication of the posterior lock assembly in the maxillary custom sectional tray:

- Cut the 2 dual die-pins that are attached to sleeves halfway through their heights (Figure 4) by using a carborundum disk (Dentorium, New York, USA). Only the broader upper halves are used for fabricating the posterior assembly and the lower halves are discarded.

- Attach the half-cut sleeves on the posterior parts of the sectioned custom tray halves using acrylic resin such that the greatest dimension of each sleeve is oriented in the anteroposterior direction. Check for parallelism between the sleeves using a dental surveyor and verify the fit of the diepins in the respective sleeves (Figure 5).

- Fabricate an acrylic resin block $16 \mathrm{~mm}$ height, $10 \mathrm{~mm}$ width, and $4 \mathrm{~mm}$ longer than the distance between the 2 attached sleeves) using the autopolymerizing acrylic resin (Figure 4).

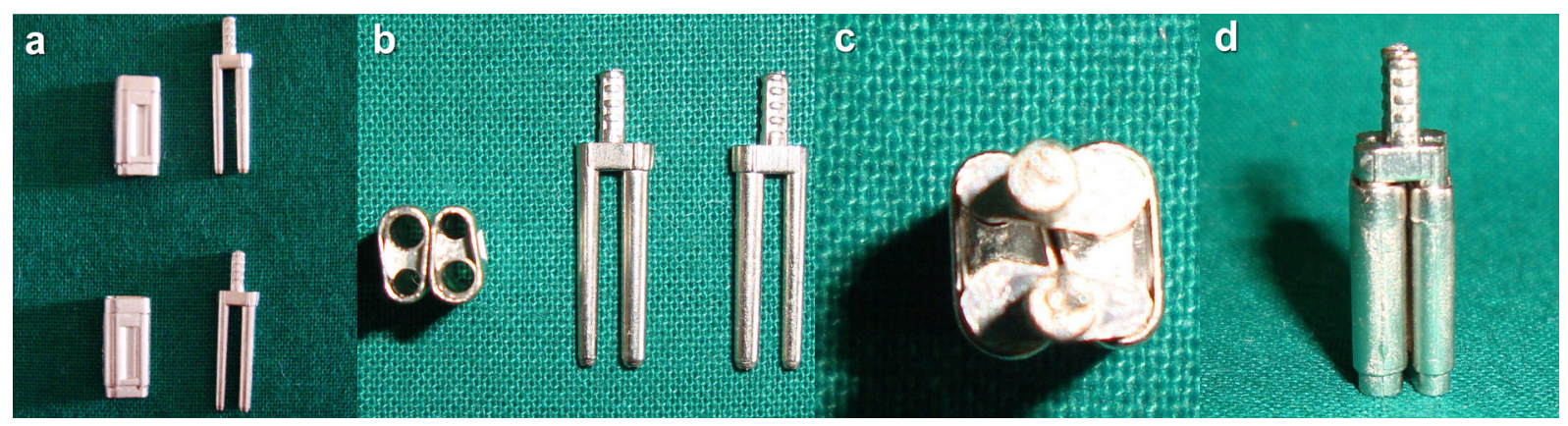

Figure 1. a-d. Basic design and components of anterior locking assembly for maxillary and mandibular sectional tray. al Dual die-pins with sleeves, bl sleeves in approximated position (Top view) and two dual die-pins, c) Dual die-pins inserted in contralateral direction making a rigid joint for anterior locking assembly (Top view), d) lateral view of anterior locking assembly. 
- Transfer the respective points of the half-cut die-pin heads on the acrylic bar by using a pressure spot indicator (Coltene ${ }^{\circledR}$ PSI, Switzerland) and drill slightly oversized holes in the acrylic bar on the marked points by using a bur (261-EF023, Brasseler, USA).

- With the closely juxtaposed sectioned trays and the die-pins of the anterior assembly placed
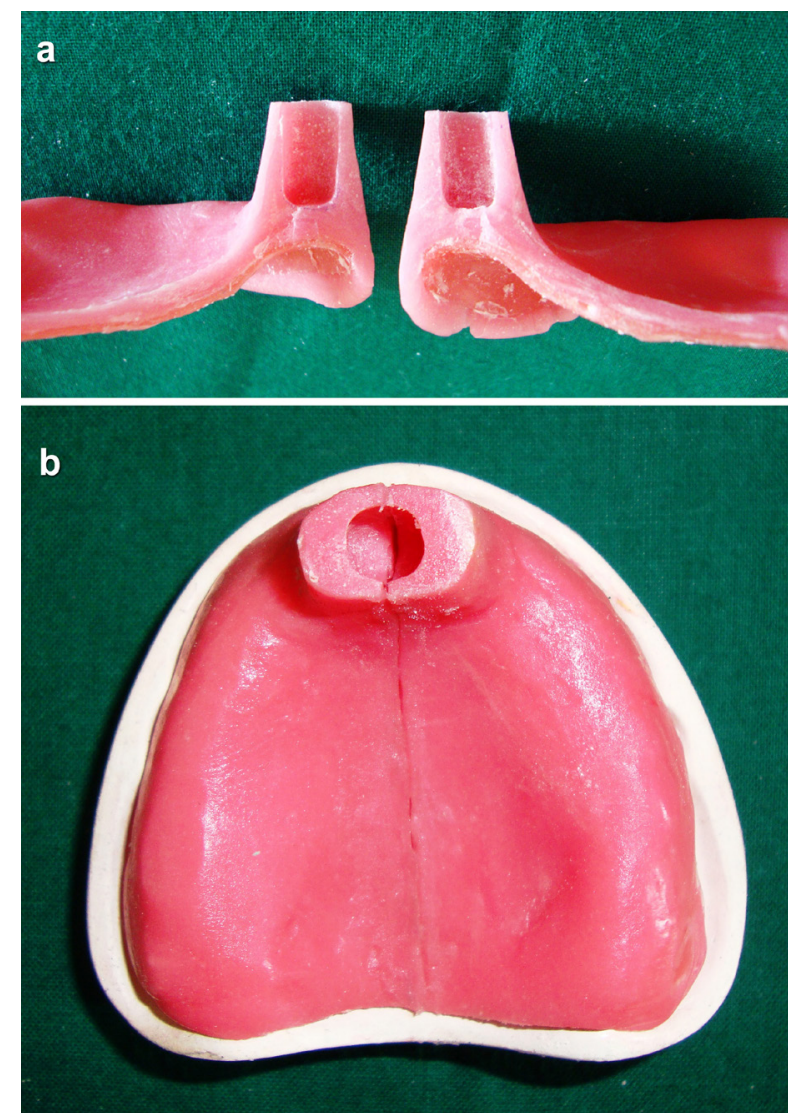

Figure 2. a-b. Slots made for attaching sleeves in each half of maxillary sectioned tray. a) Inside view, b) top view.view of anterior locking assembly.

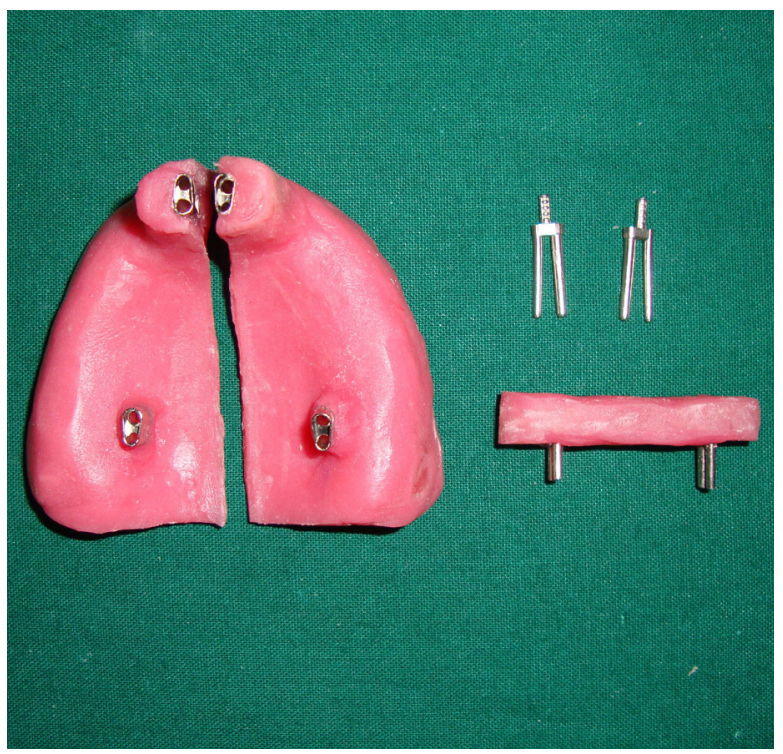

Figure 5. Half-cut sleeve positioned on each sectioned tray and corresponding pins attached to acrylic block. in position, secure the heads of the half-cut diepins into the holes by using the autopolymerizing acrylic resin (Figure 5 \& Figure 6).

\section{DISCUSSION}

The 2-piece custom-made tray described above allows for a functional impression to be made despite the difficulties associated with microstomia.

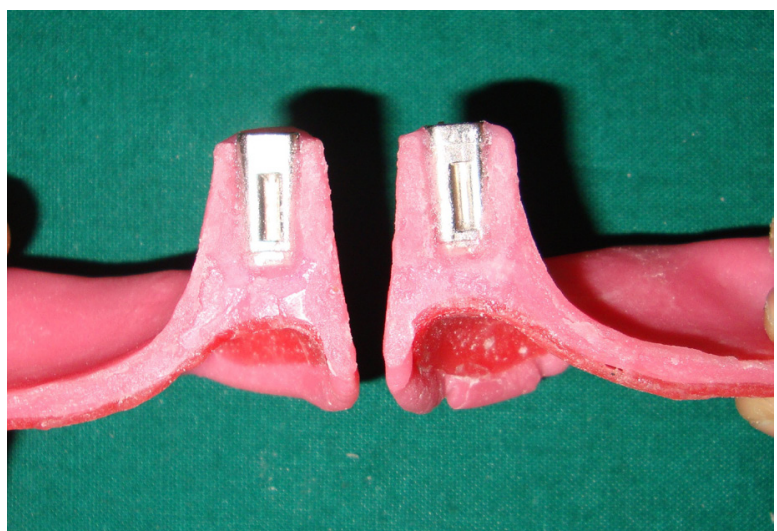

Figure 3. Sleeves attached using autopolymerising acrylic resin.

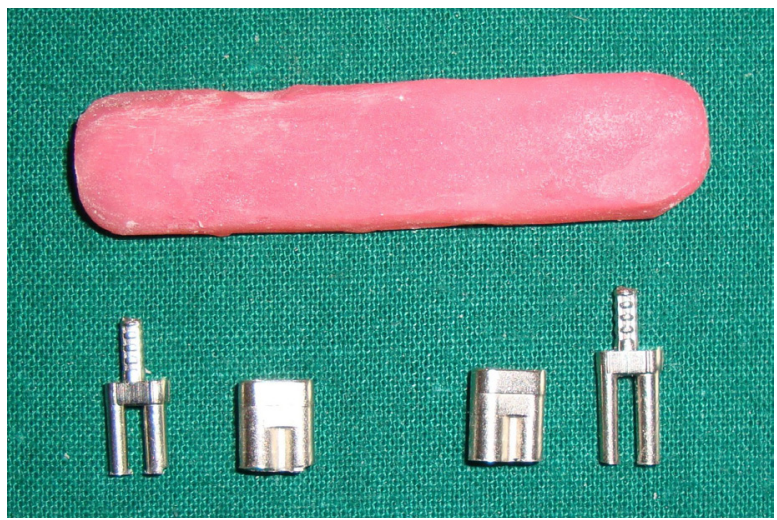

Figure 4. Components of posterior locking assembly- an acrylic block and upper halves of two dual pins and sleeves cut halfway through their height.

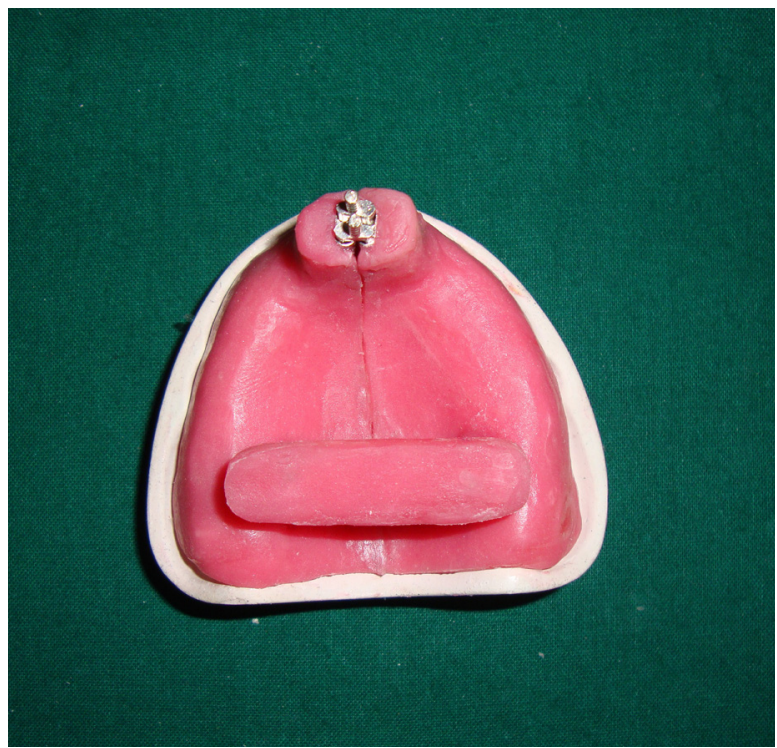

Figure 6. Completed sectional trays with both anterior and posterior locks assembled (Maxillary). 


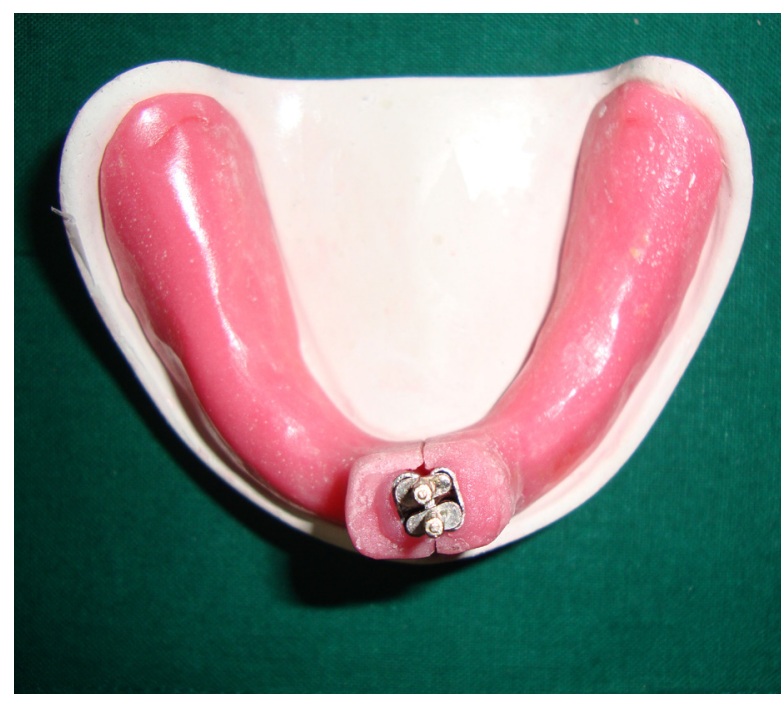

Figure 7. Completed sectional trays with anterior lock assembled (Mandibular)

The anterior locking assembly described in this article does not require any special alteration in the conventional custom tray design. The die-pins with metal sleeves used in this technique provide a greater degree of stability and a precise union of the 2 sections of the tray. It also provides a rigid joint without increasing the bulk of the tray. The joint can be made more rigid by activating the 2 prongs of each dual die-pin away from each other. This technique used for fabricating custom sectional impression trays does not require any special devices or complex locking joints. The only additional materials used are the dual die-pins which are commercially available at a minimum cost.

\section{SUMMARY}

It is often difficult to use conventional methods for fabricating dentures for patients with limited mouth opening. This article described a simple, time-saving, and cost-effective method used to fabricate custom sectional impression trays for making definitive impressions in patients with microstomia.

\section{Acknowledgements}

The authors do not have any financial interest in the companies whose materials are included in this article. The authors thank Dr. Merlin Menezes, Dr. Nandita Keni and Dr. Shweta Caculo from Goa Dental College and Hospital, Bambolim, Goa for their sincere help and suggestions in developing the technique.

\section{REFERENCES}

1. The Glossary of Prosthodontic Terms. J Prosthet Dent 2005; 94:52.

2. Smith PG, Muntz HR, Thawley SE. Local myocutaneous advancement flaps. Alternative to cross-lip and distant flaps in the reconstruction of ablative lip defects. Arch Otolaryngol 1982;108:714-718.

3. Gay WD. Prostheses for oral burn patients. J Prosthet Dent 1984;52:564-566

4. Reisberg DJ, Fine LB, Fattore L, Edmonds DC. Electrical burns of the oral commissure. J Prosthet Dent 1983;49:7176.

5. Wright GZ, Colcleugh RG, Davidge LK. Electrical burns to the commissure of the lips. J Dent Child 1977;44:377-381.

6. Dahl E, Fogh-Andersen P: Electric burns of the mouth, long-term effects on the dentition: Surgical and orthodontic considerations. Eur J Orthod 1980;2:207-217.

7. Holt GR, Parel S, Richardson DS, Kittle PE: The prosthetic management of oral commissure burns. Laryngoscope 1982;92:407-411.

8. Leake JE, Curtin JW: Electrical burns of the mouth in children. Clin Plast Surg 1984;11:669-683.

9. Koumjian JH, Firtell DN. A prosthesis to control microstomia. J Prosthet Dent 1990;64:502-503.

10. Conine TA, Carlow DL, Stevenson-Moore P. The Vancouver microstomia orthosis. J Prosthet Dent 1989;61:476-483.

11. Ampil JP, Newell L, Taylor P. A simplified prosthesis for treatment of burns to the oral cavity. J Prosthet Dent 1988;59:608-610.

12. Sela M, Tubiana I. A mouth splint for severe burns of the head and neck. J Prosthet Dent 1989;62:679-681.

13. Geckili 0 , Cilingir A, Bilgin T. Impression procedures and construction of a sectional denture for a patient with microstomia: A clinical report. J Prosthet Dent 2006;96:387390.

14. Conroy B, Reitzlic M. Prosthetic restoration in microstomia. J Prosthet Dent 1971;26:324-327.

15. Luebke RJ. Sectional impression tray for patients with constricted oral opening. J Prosthet Dent 1984;52:135-137.

16. Suzuki Y, Abe M, Hosoi T, Kurtz KS. Sectional collapsed denture for a partially edentulous patient with microstomia: a clinical report. J Prosthet Dent 2000;84:256-259.

17. Mirfazaelian A. Use of orthodontic expansion screw in fabricating section custom trays. J Prosthet Dent 2000;83:474475.

18. Baker PS, Brandt RL, Boyajian G. Impression procedure for patients with severely limited mouth opening. J Prosthet Dent 2000;84:241-244. 